Science impinges constantly on everyday life and ought to be understood at least in part. Astronomy is the most accessible science to the arts student: after all isn't every thinking person a cosmologist? Even the child ponders earth, space and time, their beginning and end. And astronomy is central among the sciences, gathering knowledge and expertise from a myriad of scientific specialities. Both the significance and insignificance of man in relationship to time and the universe are clearly illustrated.

But how should the arts student be approached? Most of the books seem to regard him as a rather stupid, inumerate, failed scientist. Surely this student has a different outlook on life from scientists, an outlook bred on comparison and criticism and aesthetic judgement, a preoccupation with why as opposed to the narrower scientific how. Science should be able to learn as much from arts students as they do from scientists, and these books should help and encourage arts students to play their part in quenching the thirst for knowledge.

Both the books under review are good in their own way. Both are clearly written in a concise and everquestioning style, continually leading the reader to grasp the enormities of the problems being tackled by astronomers and the many pitfalls on the way to understanding. Both books are lavishly illustrated with photographs of instruments, planets, stars and galaxies and, especially in Hodge's book, with thoughtfully designed simple line figures.

Each book considers basic astronomical concepts, the Solar System, stars and galaxies; however, Cole has slightly more emphasis on the Solar System, Hodge emphasising stellar evolution. Both books stress observation: Cole has an excellent appendix on observational astronomy for beginners; Hodge concludes each chapter with a fascinating list of suggestions for simple experiments and observations. Some of these require simple laboratory equipment or a small telescope or high powered binoculars but many require only impoverished equipment that can be put together at home.

Choosing between the two books I would pick Hodge's Concepts of Contemporary Astronomy: the best book on astronomy at this level that I have read for many years. Hodge has thought very carefully about the needs of the students he is writing for and gives them not only a knowledge of the nature of the universe but also an appreciation of the methods of science. But I still have a hankering to read an astronomy text written by an arts graduate. I wonder what they really make of it.

David W. Hughes

\section{Sources of streams}

Fluvial Processes in Instrumented Watersheds: Studies of Small Watersheds in the British Isles. By $\mathbf{K}$. J. Gregory and D. E. Walling. Pp. $\mathrm{iii}+194$. (Institute of British Geographers Special Publication No 6.) (Institute of British Geographers: London, February 1974.) $£ 4.25$; $\$ 10.60$.

THIS latest volume by the British Geomorphological Research Group reports the results of major process investigations in small catchments in Britain. The work involves contributions in four major areas: the origins and controls of run-off and of sediment and solutes. The objectives of the studies range from basic assessments of the volume and frequency of inputs and outputs to the basin, to formal testing of deductive models. For the most part, however, the work is empirical and much of it applied or capable of direct application. It should attract the attention of practising civil engineers as well as researchers.

Two dilemmas are brought out

\section{Earth science by numbers}

Geomathematics: Mathematical Background and Geo-Science Applications. By F. P. Agterberg. Pp. xvi+596. (Developments in Geomathematics, vol. 1.) (Elsevier: Amsterdam, London and New York, 1974.) Dfl135; \$54.00.

THIS book surveys the mathematical methods and statistical techniques used in the study of data obtained from various types of physical and chemical sampling of rock and rock strata at the Earth's surface. It is not, as its title might imply, a comprehensive survey of the mathematical methods used in general geophysics. Rock samples, and geological data generally, are characterised by very great variability and so it is not surprising that this book concentrates on probability and statistics.

The book is unique in that these statistical methods are illustrated by many examples drawn from geology. In a way it is strange that it was biology rather than geology that provided the stage for the development of modern statistical methods. Lyell had in an appendix to his Principles of Geology divided the Tertiary into four periods on the basis of the proportion of species found in these rocks living today. But on the whole the field geologist, unlike the agriculturalist, did not find it easy to record in a simple numerical form the various pieces of information he collected and perhaps remained unconvinced of the value of doing so. It was of course the long series of carefully clearly in the volume and referred to by the editors. The first is that within the basin there are important spatial and temporal variations in processes whose effects are integrated in sediment, solute and water yield at the output. Unfortunately, the output is where the monitoring of the basin is likely to be easiest and least expensive. In choosing small basins where one process tends to dominate, this dilemma has been partly avoided. Moreover, the work then becomes complementary to, rather than competitive with, that carried out by other research organisations. The second dilemma is that with the rapid development of the subject, model building alternately precedes and succeeds data collection for testing. The solution seems to be the closer integration of the two areas of research.

This is an important addition to research in geomorphology and perhaps to hydrology. Despite an over-imaginative use of the linear regression model, it indicates a very healthy state in a key area of concern in environmental research and management.

John B. Thornes

marshalled numerical data at Rothamstead that gave the late Sir Ronald Fisher the impetus he needed to lay the basis of modern statistics.

It is, however, interesting to note that the impetus from the development of a statistical theory of variation in two and three dimensions resulted from the accumulation of data on the distribution of cross bedding directions and palaeomagnetic data respectively. All this is now changed and this book will be of great value to the geologist.

S. K. Runcorn

Statistical Methods for the Earth Scientist. By Roger Till. Pp. 154. (Macmillan: London and Basingstoke, 1974.) $£ 5.00$, boards; $£ 2.50$, paper.

THERE are few really readable books on statistics in general and even fëwer aimed specifically at the earth scientist, but Dr Till is to be congratulated in joining a select and much needed band. The book is intended as the basis for a 40 hour course in statistics for undergraduate or postgraduate students with no previous background in statistics. and only simple algebra. It is a small volume -9.5 by 6 inohes - with a content ranging from the basic philosophy of statistics up to analyses of variance, regression and some non-parametric tests. These are covered in a comprehensible way with examples drawn from mainly sedimentological and geochemical sources, although care has obviously been taken to include at least 